\title{
Quadruple-negative breast cancer: novel implications for a new disease
}

\author{
Shristi Bhattarai ${ }^{1}$ Geetanjali Saini', Keerthi Gogineni ${ }^{2}$ and Ritu Aneja ${ }^{1 *}$ (D)
}

\begin{abstract}
Based on the androgen receptor (AR) expression, triple-negative breast cancer (TNBC) can be subdivided into ARpositive TNBC and AR-negative TNBC, also known as quadruple-negative breast cancer (QNBC). QNBC characterization and treatment is fraught with many challenges. In QNBC, there is a greater paucity of prognostic biomarkers and therapeutic targets than AR-positive TNBC. Although the prognostic role of AR in TNBC remains controversial, many studies revealed that a lack of AR expression confers a more aggressive disease course. Literature characterizing QNBC tumor biology and uncovering novel biomarkers for improved management of the disease remains scarce. In this comprehensive review, we summarize the current QNBC landscape and propose avenues for future research, suggesting potential biomarkers and therapeutic strategies that warrant investigation.
\end{abstract}

Keywords: Quadruple-negative breast cancer, Triple-negative breast cancer, Androgen receptor, AR antagonists, Cancer biomarkers, Therapeutic targets

\section{Introduction}

Triple-negative breast cancer (TNBC) is defined by the lack of the estrogen receptor (ER), progesterone receptor (PR), and human epidermal growth factor receptor 2 (HER2) expression [1]. Compared to other breast cancer (BC) subtypes, patients with TNBC have a more aggressive clinical course and poorer prognosis, with higher rates of local recurrence and distant metastasis within 5 years of diagnosis [2]. The disease disproportionately affects women of African ancestry and pre-menopausal women [2-5]. Mounting evidence suggests that nonbiological and epidemiological factors play a substantial role in the etiology of TNBC. Factors associated with increased risk of TNBC include African ancestry, younger age, obesity, BMI, shorter breastfeeding duration, higher parity, oral contraceptive usage for $\geq 1$ year, low socioeconomic status, a diet high in animal fat, and low physical activity. Some of these, including obesity,

\footnotetext{
* Correspondence: raneja@gsu.edu

'Department of Biology, Georgia State University, 100 Piedmont Ave, Atlanta, GA 30303, USA

Full list of author information is available at the end of the article
}

breastfeeding, and physical inactivity, have been linked to androgen secretion dysregulation.

The stark inter-patient and intra-tumoral heterogeneity render TNBC challenging to cure $[6,7]$. Based on gene expression profiling, TNBCs have been subclassified, raising the potential for more precise therapeutic intervention.

An updated version by Lehmann and colleagues classifies TNBC into four distinct molecular subtypes including two basal-like subtypes, i.e., (BL1 and BL2), mesenchymal $(\mathrm{M})$, and luminal androgen receptor (LAR) [8]. Retrospective analysis of these TNBC subtypes demonstrated significant differences in response to neoadjuvant chemotherapy between subtypes, with LAR displaying worse response and BL1 responding more favorably [9]. Additionally, Burstein et al. categorize TNBC into luminal androgen receptor (LAR), mesenchymal (MES), basal-like immunosuppressed (BLIS), and basallike immune activated (BLIA) [10].

Although TNBCs exhibit greater chemosensitivity compared to non-TNBCs, many TNBC patients diagnosed with advanced-stage disease relapse following 
treatment with conventional anthracycline/taxane-based chemotherapy [3-5]. Hence, the identification of robust prognostic biomarkers and novel therapeutic targets is of high clinical importance.

Androgen receptor (AR) is expressed in approximately $10-43 \%$ of TNBCs depending on the AR positivity cutoff used; therefore, it has emerged as a promising therapeutic target for TNBC patients [11]. AR antagonists, such as enzalutamide and bicalutamide, currently in clinical trials, are showing promising results in ARpositive TNBC patients [12-16]. However, the remaining $67 \%-90 \%$ of TNBCs that lack AR expression, also referred to as quadruple-negative breast cancers (QNBCs), do not benefit from AR antagonists, and some studies have reported a worse prognosis for QNBC patients [17-22] compared to those with AR-positive TNBC. Recent evidence suggests that QNBC differs from TNBC in its molecular and genetic make-up. This calls for extensive identification and annotation of key AR-dependent proteins and a delineation of the mechanistic action of AR. Herein, we summarize the current landscape of QNBC, implications of AR absence or presence, and rationally designed therapeutic strategies for QNBCs, as well as suggest avenues for future research in disease management.

\section{Cutting both ways: the role of AR in TNBC}

$\mathrm{AR}$ is a transcription factor (TF) belonging to the nuclear steroid hormone receptor family. AR-mediated signaling plays a critical role in the development of breast tissue [23]. There is also accumulating evidence supporting the role of $\mathrm{AR}$ in $\mathrm{BC}$ development and progression $[24,25]$. Nonetheless, the role of AR signaling in TNBC remains unclear. In TNBC, AR is reported to interact with androgen response elements (AREs) and stimulate tumor cell growth in an androgen-dependent manner. In TNBC patients, clinical trial focused on testing the antiandrogen therapies (e.g., bicalutamide, abiraterone acetate + prednisone, and enzalutamide) in combination with chemotherapy in TNBC patients have yielded positive results $[15,16,26]$. Currently, the efficacy of various drug combinations such as pembrolizumab and enobosarm, palbociclib and avelumab, and taselisib and enzalutamide is being evaluated in patients with metastatic TNBC [27-30]. In addition, the ongoing MDACC ARTE MIS trial is a neoadjuvant study that is focused on women with stage I-III TNBC and modifies therapy based on molecular profiling. For example, if AR is expressed, then enzalutamide along with paclitaxel is administered [31].

There have been conflicting reports regarding AR expression levels in TNBC, ranging from 7 to $75 \%$ [32-36]. In contrast to non-LAR subtypes, the TNBC LAR subtype is enriched in AR expression and exhibits sensitivity to AR-targeted therapies [37]. However, the prognostic role of AR in TNBC is ambiguous, with several studies associating loss of AR expression with worse prognosis in TNBC patients, and others attributing worse outcomes to increased AR signaling [14, 19-21, 33-35, 38-48]. These discrepancies are largely attributed to variability in sample procuring methods, antibodies, staining, scoring methods, and AR positivity cutoff values. The confounding effects of patient selection in prospective studies could also be a plausible factor underlying this variability [49]. We have recently conducted a multi-institutional study evaluating AR expression among different cohorts and observed that, even after accounting for these factors, the discrepancy in prognostic value persisted [50].

Additionally, AR splice variants (AR-Vs), which are produced due to structural rearrangement or alternative splicing of the AR transcript, have been suggested to underlie the variability in findings regarding the prognostic role of AR in TNBC [51]. These variants lack the entire or a part of the ligand-binding domain (LBD; the target of enzalutamide) yet remain constitutively active and activate target genes [51, 52]. Thus far, 15 different AR-Vs have been identified [53, 54]. In prostate cancer, the expression of AR-Vs has been shown to confer resistance to androgen deprivation therapy $[55,56]$. In a recent study, Hickey et al. [57] reported the expression of active AR-Vs in ERnegative breast tumors, suggesting their potential influence in the response of TNBCs to androgen deprivation therapies. The study also highlighted the role of the well-studied AR-V7 in inducing in vitro cell proliferation in the absence of enzalutamide. AR and AR-V7 differentially regulate target gene expression depending on the preferential recruitment of AR or its splice variant to specific cis-regulatory DNA sequences [58]. AR-V7 expression has recently been reported to be associated with unfavorable $\mathrm{BC}$ patient prognosis, which has increased interest in investigating this $A R-V$ as a potential therapeutic target [11, 59]. Limited data on AR-V7 and other AR-Vs exists in $\mathrm{BC}$; thus, further investigation into the different AR-Vs may help resolve the controversial prognostic role of AR in TNBC patients.

AR can drive tumor growth even in TNBC subtypes expressing low levels of AR. Although the precise mechanisms remain unclear, the AR-positive tumor cell subpopulation can support the growth of a cancer stem cell (CSC)-like cells, which promote chemotherapy resistance and tumor recurrence. Thus, AR-targeting agents may still be beneficial for TNBC patients exhibiting low $(\leq 1 \%)$ AR expression [60]. Compared with paclitaxel alone, the combination of enzalutamide and paclitaxel is believed to be more effective in preventing recurrence by targeting CSC-like cells. 
Augmenting the complexity of the subject further, prognostic implications of AR expression appear to vary by ancestry. A recent AR assessment study [61] found that TNBC in women of African ancestry (AA) was associated with a higher frequency of AR expression loss. Furthermore, AAs with AR-negative TNBC had worse overall survival than women of European ancestry (EA). AA women with AR-negative TNBC were found to express a unique molecular signature and were enriched for BL1, BL2, and IM subtypes.

In contrast to ER, PR, and HER2 testing, which is standard clinical practice, AR testing has not been standardized due to the lack of consensus regarding its prognostic value. However, given expanding data revealing that QNBC tumors have a more aggressive disease course and worse outcomes than AR-positive tumors, standardizing AR testing is critical. QNBC has a distinct molecular profile and should be considered a separate entity from TNBC. TNBC heterogeneity is associated with AR expression, suggesting that QNBC is a distinct, clinically relevant subtype [62]. Differences in tumor biology between QNBC and TNBC can be exploited to yield novel therapies for targeted management of ARnegative and AR-positive TNBCs. Table 1 captures these distinctions and corresponding potential therapeutic interventions for AR-negative TNBC patients (also see Fig. 1).

Although the prognostic value of AR is ambiguous, there is better agreement on its predictive value. A study by Masuda et al. [100] demonstrated that among TNBC subtypes, BL1 had the highest pathological complete response (pCR) rate $(52 \%)$ after neoadjuvant chemotherapy (NAC), while BL2 and LAR had the lowest. Low AR levels were associated with higher $\mathrm{pCR}$ rates in a clinical trial evaluating neoadjuvant cisplatin plus paclitaxel with or without everolimus in a TNBC cohort [101]. Another study found that AR could predict tamoxifen treatment benefit in TNBC patients, where AR-positive patients benefited from the treatment, whereas patients with ARnegative tumors progressed after tamoxifen treatment [102]. Altogether, AR status testing can aid in neoadjuvant treatment decision-making.

\section{In-depth mapping of the QNBC terrain: unearthing novel targets}

Protein expression analysis, gene copy number analysis, and gene sequencing have yielded promising therapeutic targets for TNBC (Fig. 1). A recent integrated network analysis and machine learning approach identified key genes and pathways to help distinguish TNBCs from non-TNBCs [103]. In contrast, genome wide studies examining differences between AR-positive TNBCs and AR-negative QNBCs are extremely scarce. QNBCs are not yet explicitly classified as a separate $\mathrm{BC}$ subtype and are overshadowed by the greater focus that TNBC research receives. In addition, within TNBCs, more AA women tend to be AR-negative/QNBC, a demographic that is persistently under-represented in clinical studies and public datasets such as TCGA. In this section, we review the limited available data exploring potential biomarkers in QNBC that may serve as therapeutic targets. Further study of whether druggable targets overexpressed in TNBC are also overexpressed in QNBC is warranted. Results from the Caris Research Institute corroborated higher expression of EGFR and TOPO2A in QNBC compared to AR-positive TNBCs, as well as indicated significantly higher expression of c-KIT and thymidylate synthase (TS) [104]. C-Kit is a receptor tyrosine kinase (RTK), and an increased gene copy number has been linked to an aggressive phenotype and unfavorable prognosis in TNBC [105]. Jansson et al. [106] also observed higher protein levels of c-KIT and two other RTKs, vascular endothelial growth factor receptor2 (VEGFR2), and platelet-derived growth factor receptor alpha (PDGFR $\alpha$ ), in TNBC compared to non-TNBC [107-110]. Specimens obtained in trials targeting these markers in TNBC should be interrogated for AR status and whether response varies by AR status. Small molecule inhibitors and monoclonal antibodies are the main RTK-targeting therapeutic approaches under development in TNBC. Both FDA-approved and investigational drugs such as imatinib, cabozantinib, dasatinib, lucitanib, and sunitinib (inhibits kinases and/or VEGFR, FGFR, PDGFR) are being evaluated in TNBC patients [107111 ] and could be of value in QNBCs as well. TS catalyzes the conversion of deoxyuridine monophosphate (dUMP) to deoxythymidine monophosphate (dTMP) and is involved in nucleotide metabolism, which is often boosted in cancer cells to sustain increased proliferation. A 2019 study reported significantly high levels of TS in TNBC compared to luminal $\mathrm{BC}$ subtypes, which correlated with worse prognosis and could prove to be a valuable prognostic biomarker and therapeutic target in QNBC [112].

Davis et al. [61] identified gene expression differences in AR-deficient versus AR-expressing $\mathrm{BC}$ patients by race, providing a template to advance $\mathrm{QNBC}$ research. A comprehensive assessment of AR expression within all BC subtypes from The Cancer Genome Atlas (TCGA) revealed that women of AA were more likely to lack $A R$ expression than White women. The association between AR expression and race was strongest in TNBC. These findings highlight the need for extensive race-specific annotation of genes associated with AR-negative BC. Further examination of AR-negative BCs for a distinctive gene expression profile has uncovered differential expression of several immune-related genes by race, including E2F1, PDK1, CCL2, CEBPB, NFKBIL2, TGFB3, IL12RB2, IL2RA, and SOS1 (Fig. 1). 
Table 1 QNBC biomarkers and therapeutic targets, based upon differences in tumor biology between AR-negative and AR-positive TNBCs, and suggested therapeutic interventions

\begin{tabular}{|c|c|c|}
\hline $\begin{array}{l}\text { QNBC biomarkers and } \\
\text { therapeutic targets }\end{array}$ & $\begin{array}{l}\text { Genomic and molecular features (relative } \\
\text { expression to } A R+\text { ) }\end{array}$ & Prospective therapy \\
\hline \multicolumn{3}{|l|}{ Cell growth and proliferation } \\
\hline $\begin{array}{l}\text { EGFR (epidermal growth factor } \\
\text { receptor) }\end{array}$ & $\begin{array}{l}\text { Higher expression; indicates increased cellular } \\
\text { growth and proliferation }\end{array}$ & $\begin{array}{l}\text { Tyrosine kinase inhibitors (gefitinib and erlotinib) and } \\
\text { anti-EGFR monoclonal antibodies (cetuximab) [63-67] }\end{array}$ \\
\hline $\begin{array}{l}\text { HER4 (human epidermal growth } \\
\text { factor receptor 4) }\end{array}$ & $\begin{array}{l}\text { Lack of expression; may serve as a prognostic } \\
\text { biomarker }\end{array}$ & $\begin{array}{l}\text { Not a therapeutic target; only a prognostic } \\
\text { biomarker [68-70] }\end{array}$ \\
\hline Ki-67 & $\begin{array}{l}\text { Enhanced expression, i.e., high proliferation } \\
\text { index }\end{array}$ & Anthracycline/taxane-based chemotherapy $[12,71-76]$ \\
\hline CK 5/6 (cytokeratin 5/6) & Enhanced expression & \\
\hline TOPO2A (topoisomerase lla) & Elevated levels & \multirow{2}{*}{$\begin{array}{l}\text { Anthracycline, topoisomerase } 1 / 1 / \text { inhibitors and } \\
\text { PI3K/AKT/mTOR inhibitors }[77,78]\end{array}$} \\
\hline PTEN (phosphatase and tensin) & Decreased expression & \\
\hline CDK6 (cyclin-dependent kinase 6) & Increased mRNA expression & CDK4/6 inhibitors (palbociclib, trilaciclib) $[79,80]$ \\
\hline \multicolumn{3}{|l|}{ Cell metabolism } \\
\hline \multirow[t]{2}{*}{ ASCL4 (acyl-CoA synthetase 4) } & $\begin{array}{l}\text { - Elevated expression associated with claudin- } \\
\text { low and basal-like BC phenotypes; may } \\
\text { boost arachidonic acid metabolism through } \\
\text { PTGS2, ALOX5, and AKT/mTOR pathways }\end{array}$ & $\begin{array}{l}\text { - Synergistic effect of ACSL4 inhibitor (e.g., rosiglitazone) } \\
\text { and mTOR inhibitor (e.g., rapamycin) }\end{array}$ \\
\hline & - May serve as a therapeutic biomarker & $\begin{array}{l}\text { - Downregulation of ASCL4 upregulates ER and AR } \\
\text { expression in vitro; ASCL4 inhibition may create } \\
\text { sensitivity to hormone-targeted therapies such as } \\
\text { tamoxifen and anti-AR agents [81-85] }\end{array}$ \\
\hline \multicolumn{3}{|l|}{ Tumor immune microenvironment } \\
\hline $\begin{array}{l}\text { PD-L1 (programmed death- } \\
\text { ligand 1) }\end{array}$ & Higher expression & Immune checkpoint inhibitors (i.e., pembrolizumab) [86] \\
\hline $\begin{array}{l}\text { TIL (tumor-infiltrating } \\
\text { lymphocytes) }\end{array}$ & $\begin{array}{l}\text { Higher peripheral and stromal levels (suggests } \\
\text { increased anti-tumor immune activity); } \\
\text { positively correlates with EGFR, BRCA1, } \\
\beta \text {-catenin expression in early-stage QNBC }\end{array}$ & $\begin{array}{l}\text { EGFR-targeted therapies, platinum agents, and } \\
\text { Wnt/ } \beta \text {-catenin small molecule inhibitors [87-89] }\end{array}$ \\
\hline $\begin{array}{l}\text { TNFSF10 (tumor necrosis factor } \\
\text { superfamily member 10) }\end{array}$ & $\begin{array}{l}\text { Lower mRNA expression (suggests decreased } \\
\text { anti-tumor immune activity) }\end{array}$ & $\begin{array}{l}\text { Potential susceptibility to cytokine-based immunotherapy } \\
\text { to stimulate anti-tumoral immunity }[68,90]\end{array}$ \\
\hline \multicolumn{3}{|l|}{ Organellular level } \\
\hline CA20 gene set & $\begin{array}{l}\text { Higher centrosome amplification (CA) and CA20 } \\
\text { score }\end{array}$ & $\begin{array}{l}\text { Centrosome declustering drugs (griseofulvin, } \\
\text { noscapine), HSET inhibitors (CW069, AZ82), PARPi } \\
\text { (PJ34, GF-15) [91-99] }\end{array}$ \\
\hline
\end{tabular}

\section{E2F1 and angiogenesis markers}

E2F1 belongs to a class of TFs involved in G1/S transition and is being touted as a master regulator of $\mathrm{BC}$ metastasis [113]. Non-steroidal anti-inflammatory drugs such as diclofenac and indomethacin were found to downregulate E2F1, among other genes, and inhibit cell growth in ovarian cancer cell lines [114]. E2F1 affects the activity of several key signaling pathways, including hypoxia and angiogenesis, both of which are considered hallmarks of cancer [113]. E2F1 modulates angiogenesis via vascular endothelial growth factor (VEGF), its key facilitator $[115,116]$. A significantly higher expression of VEGF has been observed in TNBCs compared to nonTNBCs [117]. Nevertheless, the role of angiogenesis in QNBC remains elusive. VEGF signaling is reportedly upregulated by EGFR expression, which is also significantly higher among QNBCs compared to AR+ TNBCs [118].
Clinical trials testing VEGF inhibitors, such as bevacizumab, in combination with cytotoxic chemotherapy or other antiangiogenic agents in metastatic BC and TNBC patients, have shown an improved patient response [119]. Extensive studies assessing the role of other key angiogenesis markers in addition to VEGF, such as mTOR, fibroblast growth factor (FGF), Notch, hypoxicinducible factor (HIF), and insulin growth factor (IGF), as potential novel therapeutic targets in QNBC are required.

\section{Mediators of hypoxia}

Interestingly, mediators of hypoxia, such as HIF TFs (HIF- $1 \alpha$ and HIF $2 \alpha$ ) and carbonic anhydrase IX (CAIX), are highly upregulated in TNBCs compared to nonTNBCs [120, 121]. Moreover, high CAIX expression has been associated with poor disease-free survival (DFS) 


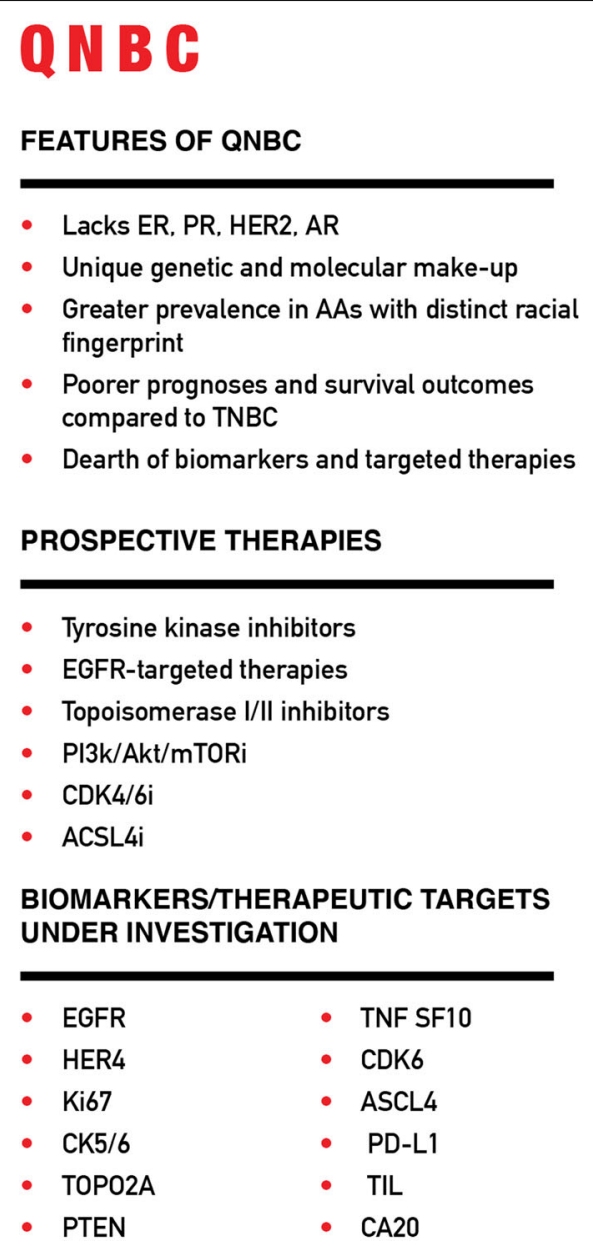

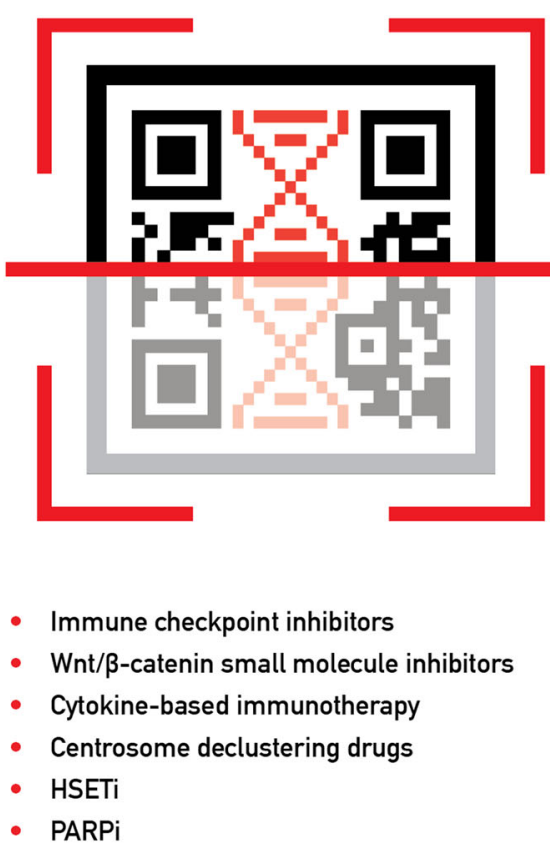

POTENTIAL BIOMARKERS

\begin{tabular}{ll}
\hline - $\mathrm{CKIT}$ & CAIX \\
- HIF-1 & - CEBPB \\
- CCL2 & E2F1 \\
- SKP2 & - VEGF \\
- TS & EN1
\end{tabular}

Fig. 1 Overview of the distinct features of QNBC as well as biomarkers/therapeutic targets and therapies under investigation. QNBC is clustered with the TNBC subtype despite having a unique molecular landscape. QNBC warrants an in-depth annotation and should be considered a separate BC subtype

and overall survival (OS) among AR-negative/ER-negative BC patients [122]. HIF1- $\alpha$ downregulation in TNBC cells promoted apoptosis and impaired cell invasion and migration, while CAIX silencing in metastatic BC mouse models resulted in regression of orthotopic mammary tumors. Hence, it may be useful to investigate differences in hypoxia-induced proteins between AR-negative and AR-positive TNBCs to determine whether targeting HIF1- $\alpha$ and CAIX will be beneficial in QNBC $[123,124]$. HIF-1 and CAIX small molecule inhibitors and monoclonal antibodies are currently in preclinical and early clinical testing $[123,125]$.

\section{PDK1}

One of the differentially expressed genes in QNBC identified by Davis et al. is 3-phosphoinositide-dependent protein kinase-1 (PDK1), a downstream effector of PI3K [61]. The role of PDK in carcinogenesis is suggested to be PIK3/AKT pathway-dependent; however, in BC, PDK1 is also believed to be activated in a PIK3/AKT- independent manner [126, 127]. PDK1 depletion has been shown to delay tumor initiation, progression, and metastasis in a BC mouse model [128]. Thus, the PDK1 signaling pathway may represent a viable therapeutic target in QNBC. 2-O-Bn-InsP5 (M. Falasca Laboratory), GSK2334470 (GlaxoSmithKline), OXIDs (S. Rapposelli Laboratory), and MP7 (Merck) are some of the PDK1 inhibitors under investigation [129].

\section{Tumor immune landscape}

The chemokine CCL2 is involved in tumor development and progression by promoting the migration and infiltration of monocytes and tumor-associated macrophages (TAMs) [130]. CCL2 overexpression has been associated with poor patient prognosis in various tumor types, including BC [131]. TAMs and tumor-associated neutrophils (TANs) are significantly more prevalent in TNBC than in hormone receptor-positive BC [132-134]. Although TAMs and TANs participate in anti-tumor immunity, they can also switch from a pro-inflammatory 
cell phenotype to a pro-tumoral one. One of the immunosuppressive functions of TAMs in TNBC is the induction of the co-inhibitory molecules PD-1 and TIM-3 [135]. While CCL2 is a potential molecular target, therapeutic intervention using neutralizing antibodies against CCL2 has not yielded the desired impact. Using a novel gene silencing approach, Fang et al. [131] were able to target CCL2 more effectively, inhibiting TNBC progression by blocking CSC renewal and M2 macrophage recruitment. Therapeutic strategies to suppress the protumoral functions of TAMs and TANs are currently under investigation [136, 137]. Expression of CD4+ and $\mathrm{CD} 8+\mathrm{T}$ cell markers along with that of the immune checkpoint molecules PD-1, PD-L1, and CTLA-4 was found to be significantly upregulated in QNBC compared with AR-positive TNBC [61]. Therefore, it may be worthwhile to investigate differential expression of other immune checkpoint molecules, such as LAG-3 and TIM-3. In addition to PD-L1 inhibitors, immune checkpoint inhibitors targeting CTLA-4 and LAG-3, such as ipilimumab and IMP321, have reached phase III and I/II clinical trials, respectively, and have shown promising results [138]. A comprehensive elucidation of the QNBC immune landscape could be invaluable for risk prognostication and targeted immunotherapeutic intervention.

\section{Micro-RNAs}

Shi et al. [139] identified 153 micro-RNAs (miRNAs) that were differentially expressed between QNBC and AR-positive molecular subtypes, affecting several signaling pathways involved in tumor cell proliferation and invasion. Another study using TCGA data identified 40 miRNAs with differential expression in QNBC. Interestingly, these miRNAs were associated with race and $\mathrm{BC}$ subtype [62]. Current efforts are focused on the development of therapeutic strategies targeting miRNAs in cancer and other diseases, such as miRNA mimics and antimiRNAs. The identification of QNBC-specific circulating miRNAs may also improve detection and prognosis.

\section{Transcription factors: CEBPB and EN1}

The CCAAT enhancer-binding protein beta (CEBPB) is a TF regulating the expression of genes involved in inflammatory responses. High CEBPB has been correlated with expression of the chromosome 19 miRNA cluster (C19MC), the expression of which has been linked to TNBC [140]. Due to this association, it may also be worthwhile to compare C19MC expression in QNBC versus TNBC. The fact that CEBPB is induced under hypoxic conditions [141] further emphasizes the need to determine the role of hypoxia in QNBC.

From analyses in TCGA datasets, Peluffo G et al. [142] identified 17 TFs that were significantly upregulated in TNBCs and focused on delineating the role of
Engrailed-1 (EN1), a neural-specific TF. They found that downregulation of EN1 in TNBC cell lines significantly reduced viability and tumorigenicity, as well as affected the expression of genes involved in WNT and Hedgehog signaling pathways [142]. Furthermore, high EN1 expression levels were associated with brain metastasis and poor OS. In a different study, EN1 expression was associated with unfavorable OS in QNBC patients. It has been proposed that EN1 may promote the proliferation, migration, and multinucleation of QNBC cells via the transcriptional activation of HDAC8, UTP11L, and ZIC3 [143]. In the same study, the ability of actinomycin to inhibit EN1 was also shown. Recently, multi-functionalized nanoparticles have been formulated to specifically target EN1 with less toxicity; these await further testing in clinical trials [144]. Notably, Peluffo G et al. identified the TF CEBPB, peroxisome proliferator-activated receptor delta (PPARD), and thyroid hormone receptorinteracting protein 13 (TRIP13) as promising potential biomarkers for QNBC [142].

\section{SKP2}

As part of the SCF-SKP2 ubiquitin ligase complex, Sphase kinase-associated protein 2 (SKP2) is involved in the degradation of p21, p27 (a CDK inhibitor), and p57, among other proteins. SKP2 is a known oncoprotein being involved in DNA replication during the S-phase of the cell cycle [145]. SKP2 was identified as one of the key genes upregulated in TNBC compared to non-TNBC samples [103]. Although the impact of the differential expression of SKP2 between QNBC and TNBC remains unclear, AR was identified as an upstream regulator of SKP2 in prostate cancer cells. Additionally, AR expression levels were negatively correlated with SKP2 expression levels, and SKP2 overexpression resulted in reduced AR expression and activity [139, 146-150]. The association between SKP2 and negative AR status underpins SKP2 as a potential therapeutic target in QNBC. A small molecular inhibitor is currently being developed to inhibit SKP2-p26 interaction and subsequent p27 degradation [151].

\section{Conclusions: future perspectives and implementation}

QNBC is an aggressive and poorly understood form of BC. This review presents recent findings that aimed to improve our understanding of QNBC tumor biology required to identify prognostic markers and therapeutic targets. Studies assessing the differential expression of biomarkers between QNBCs and TNBCs may yield novel actionable targets unique to QNBC. These discoveries may also benefit TNBC patients of African ancestry, who are predominantly diagnosed with a QNBC phenotype. Cumulative evidence suggests that QNBC is highly proliferative and immunogenic, rendering it an 
ideal candidate for cytotoxic chemotherapy and immunotherapy. However, QNBCs have worse clinical outcomes even after treatment with adjuvant chemotherapy. Besides, acquired resistance to taxanes is also commonly observed. Thus, combining these approaches with agents targeting QNBC biomarkers may enhance treatment response and improve prognosis.

A vast majority of these markers can be evaluated through clinically applicable methods such as immunohistochemistry (IHC). However, the successful characterization of QNBC patients and tailored clinical decision-making required the establishment of robust AR expression cutoffs. Although nuclear staining indicates active AR signaling, there is currently no standard scoring method for nuclear AR IHC staining. Often, CAP/ASCO staining guidelines for ER and PR are applied for AR since they stain similarly; however, there is no consensus on the threshold value for AR status assessment. One way to overcome this is to measure AR levels using a more reliable androgen-driven gene signature. Determining prior treatment, clinical outcomes, and key AR-dependent proteins, which may differ according to $\mathrm{BC}$ subtypes, will shed more light on the mechanistic action and prognostic value of AR in TNBC required for its implementation into routine clinical testing.

It is imperative to treat QNBC as a unique disease and thoroughly investigate its biology. Examining the role of epidemiological and non-biological factors in QNBC is equally important in gaining a holistic understanding of its etiology and uncovering novel modifiable risk factors.

\section{Acknowledgements}

NA

\section{Authors' contributions}

SB and RA: conceptualization. SB and GS: manuscript writing and editing. SB, GS, KG, and RA: editing and proof-reading the manuscript. The authors read and approved the final manuscript.

\section{Funding}

This study was supported by a grant from the National Cancer Institutes of Health (R01CA239120) to RA.

\section{Availability of data and materials}

NA

\section{Ethics approval and consent to participate}

NA

\section{Consent for publication}

NA

\section{Competing interests}

The authors declare no competing interest.

\section{Author details}

'Department of Biology, Georgia State University, 100 Piedmont Ave, Atlanta, GA 30303, USA. ${ }^{2}$ Department of Hematology and Medical Oncology, Emory University School of Medicine, Atlanta, GA 30322, USA.
Received: 30 June 2020 Accepted: 8 November 2020

Published online: 19 November 2020

\section{References}

1. Perou CM, Sorlie T, Eisen MB, van de Rijn M, Jeffrey SS, Rees CA, et al. Molecular portraits of human breast tumours. Nature. 2000;406(6797):74752.

2. Dent R, Trudeau M, Pritchard Kl, Hanna WM, Kahn HK, Sawka CA, et al. Triple-negative breast cancer: clinical features and patterns of recurrence. Clin Cancer Research. 2007;13(15 Pt 1):4429-34.

3. Bonotto M, Gerratana L, Poletto E, Driol P, Giangreco M, Russo S, et al. Measures of outcome in metastatic breast cancer: insights from a real-world scenario. Oncologist. 2014;19(6):608-15.

4. Kohler BA, Sherman RL, Howlader N, Jemal A, Ryerson AB, Henry KA, et al. Annual report to the nation on the status of cancer, 1975-2011, featuring incidence of breast cancer subtypes by race/ethnicity, poverty, and state. J National Cancer Institute. 2015;107(6):djv048.

5. Liedtke C, Mazouni C, Hess KR, Andre F, Tordai A, Mejia JA, et al. Response to neoadjuvant therapy and long-term survival in patients with triplenegative breast cancer. J Clin Oncol. 2008;26(8):1275-81.

6. Bianchini G, Balko JM, Mayer IA, Sanders ME, Gianni L. Triple-negative breast cancer: challenges and opportunities of a heterogeneous disease. Nat Rev Clin Oncol. 2016;13(11):674-90.

7. Wright N, Rida PCG, Aneja R. Tackling intra- and inter-tumor heterogeneity to combat triple negative breast cancer. Front Bioscience (Landmark edition). 2017;22:1549-80.

8. Lehmann BD, Jovanović B, Chen X, Estrada MV, Johnson KN, Shyr Y, et al. Refinement of triple-negative breast cancer molecular subtypes: implications for neoadjuvant chemotherapy selection. PLoS One. 2016;11(6): e0157368.

9. Echavarria I, López-Tarruella S, Picornell A, García-Saenz J, Jerez Y, Hoadley K et al. Pathological response in a triple-negative breast cancer cohort treated with neoadjuvant carboplatin and docetaxel according to Lehmann's refined classification. Clin Cancer Res. 2018;24(8):1845-52.

10. Burstein MD, Tsimelzon A, Poage GM, Covington KR, Contreras A, Fuqua SA, et al. Comprehensive genomic analysis identifies novel subtypes and targets of triple-negative breast cancer. Clin Cancer Research. 2015;21(7):1688-98.

11. Hon JD, Singh B, Sahin A, Du G, Wang J, Wang W, et al. Breast cancer molecular subtypes: from TNBC to QNBC. Am J Cancer Res. 2016:6(9):186472.

12. Barton VN, D'Amato NC, Gordon MA, Christenson JL, Elias A, Richer JK. Androgen receptor biology in triple negative breast cancer: a case for classification as AR+ or quadruple negative disease. Hormones Cancer. 2015; 6(5-6):206-13.

13. Caiazza F, Murray A, Madden SF, Synnott NC, Ryan EJ, O'Donovan N, et al. Preclinical evaluation of the AR inhibitor enzalutamide in triple-negative breast cancer cells. Endocr Relat Cancer. 2016;23(4):323-34.

14. Cochrane DR, Bernales S, Jacobsen BM, Cittelly DM, Howe EN, D'Amato NC, et al. Role of the androgen receptor in breast cancer and preclinical analysis of enzalutamide. Breast Cancer Res. 2014;16(1):R7.

15. Gucalp A, Tolaney S, Isakoff SJ, Ingle JN, Liu MC, Carey LA, et al. Phase II trial of bicalutamide in patients with androgen receptor-positive, estrogen receptor-negative metastatic breast cancer. Clin Cancer Research. 2013; 19(19):5505-12.

16. Traina TA, Miller K, Yardley DA, Eakle J, Schwartzberg LS, O'Shaughnessy J, et al. Enzalutamide for the treatment of androgen receptor-expressing triple-negative breast cancer. J Clin Oncol. 2018;36(9):884-90.

17. Doane AS, Danso M, Lal P, Donaton M, Zhang L, Hudis C, et al. An estrogen receptor-negative breast cancer subset characterized by a hormonally regulated transcriptional program and response to androgen. Oncogene. 2006;25(28):3994-4008.

18. Gucalp A, Traina TA. Triple-negative breast cancer: role of the androgen receptor. Cancer J. 2010;16(1):62-5

19. He J, Peng R, Yuan Z, Wang S, Peng J, Lin G, et al. Prognostic value of androgen receptor expression in operable triple-negative breast cancer: a retrospective analysis based on a tissue microarray. Medical Oncol. 2012; 29(2):406-10.

20. Luo X, Shi YX, Li ZM, Jiang WQ. Expression and clinical significance of androgen receptor in triple negative breast cancer. Chinese J Cancer. 2010; 29(6):585-90. 
21. Rakha EA, El-Sayed ME, Green AR, Lee AH, Robertson JF, Ellis IO. Prognostic markers in triple-negative breast cancer. Cancer. 2007;109(1):25-32.

22. Yu Q, Niu Y, Liu N, Zhang JZ, Liu TJ, Zhang RJ, et al. Expression of androgen receptor in breast cancer and its significance as a prognostic factor. Ann Oncol. 2011;22(6):1288-94.

23. Yeh $\mathrm{S}, \mathrm{Hu}$ YC, Wang $\mathrm{PH}$, Xie C, Xu Q, Tsai MY, et al. Abnormal mammary gland development and growth retardation in female mice and MCF7 breast cancer cells lacking androgen receptor. J Exp Med. 2003;198(12): 1899-908.

24. Peters AA, Buchanan G, Ricciardelli C, Bianco-Miotto T, Centenera MM, Harris $J M$, et al. Androgen receptor inhibits estrogen receptor-al pha activity and is prognostic in breast cancer. Cancer Res. 2009;69(15):6131-40.

25. Wong YC, Xie B. The role of androgens in mammary carcinogenesis. Italian J Anatomy Embryol. 2001;106(2 Suppl 1):111-25.

26. Bonnefoi H, Grellety T, Tredan O, Saghatchian M, Dalenc F, Mailliez A, et al. A phase II trial of abiraterone acetate plus prednisone in patients with triple-negative androgen receptor positive locally advanced or metastatic breast cancer (UCBG 12-1). Ann Oncol. 2016;27(5):812-8.

27. Bardia A, Dacosta NA, Gabrail NY, Lemon S, Danso MA, Ali HY, et al. Phase (Ph) 1 study of oral seviteronel (VT-464), a dual CYP17-Lyase (L) inhibitor and androgen receptor (AR) antagonist, in patients (pts) with advanced AR+ triple negative (TNBC) or estrogen receptor (ER)+ breast cancer (BC). J Clin Oncol. 2016;34(15_suppl):1088.

28. Lee-Bitar JS, Frankel PH, Yost SE, Synold TW, Martinez N, Tang A, et al. A phase II clinical trial of pembrolizumab and selective androgen receptor modulator GTx-024 in patients with advanced androgen receptor-positive triple-negative breast cancer. J Clin Oncol. 2019;37(15_suppl):1069.

29. Lehmann BD, Abramson VG, Sanders ME, Mayer EL, Haddad TC, Nanda R, et al. TBCRC 032 IB/II multicenter study: molecular insights to AR antagonist and PI3K inhibitor efficacy in patients with AR+ metastatic triple-negative breast cancer. Clin Cancer Res 2020;26(9):2111.

30. Mayer EL, Wander SA, Regan MM, DeMichele A, Forero-Torres A, Rimawi MF, et al. Palbociclib after CDK and endocrine therapy (PACE): a randomized phase II study of fulvestrant, palbociclib, and avelumab for endocrine pretreated ER+/HER2- metastatic breast cancer. J Clin Oncol. 2018;36(15_suppl): TPS1104-TPS.

31. Lim B, Seth S, Huo L, Layman RM, Valero V, Thompson AM, et al. Comprehensive profiling of androgen receptor-positive (AR+) triplenegative breast cancer (TNBC) patients (pts) treated with standard neoadjuvant therapy (NAT) +/- enzalutamide. J Clin Oncol. 2020;38(15_ suppl):517-

32. Mirzania M. Approach to the triple negative breast cancer in new drugs area. Int J Hematol-Oncol Stem Cell Res. 2016;10(2):115-9.

33. Park S, Koo J, Park HS, Kim JH, Choi SY, Lee JH, et al. Expression of androgen receptors in primary breast cancer. Ann Oncol. 2010;21(3):488-92.

34. Sutton LM, Cao D, Sarode V, Molberg KH, Torgbe K, Haley B, et al. Decreased androgen receptor expression is associated with distant metastases in patients with androgen receptor-expressing triple-negative breast carcinoma. Am J Clin Pathol. 2012;138(4):511-6.

35. Tang D, Xu S, Zhang Q, Zhao W. The expression and clinical significance of the androgen receptor and E-cadherin in triple-negative breast cancer. Med Oncol. 2012;29(2):526-33.

36. Yue $Y$, Astvatsaturyan $K$, Cui X, Zhang X, Fraass B, Bose $S$. Stratification of prognosis of triple-negative breast cancer patients using combinatorial biomarkers. PLoS One. 2016;11(3):e0149661.

37. Lehmann BD, Bauer JA, Chen X, Sanders ME, Chakravarthy AB, Shyr Y, et al. Identification of human triple-negative breast cancer subtypes and preclinical models for selection of targeted therapies. J Clin Invest. 2011; 121(7):2750-67.

38. Asano Y, Kashiwagi S, Goto W, Tanaka S, Morisaki T, Takashima T, et al. Expression and clinical significance of androgen receptor in triple-negative breast cancer. Cancers. 2017;9(1):4.

39. Choi JE, Kang SH, Lee SJ, Bae YK. Androgen receptor expression predicts decreased survival in early stage triple-negative breast cancer. Ann Surg Oncol. 2015;22(1):82-9.

40. Adamo B, Ricciardi GRR, leni A, Franchina T, Fazzari C, Sanò MV, et al. The prognostic significance of combined androgen receptor, E-Cadherin, Ki67 and CK5/6 expression in patients with triple negative breast cancer. Oncotarget. 2017;8(44):76974-86.

41. Constantinou C, Papadopoulos S, Karyda E, Alexopoulos A, Agnanti N, Batistatou A, et al. Expression and clinical significance of Claudin-7, PDL-1,
PTEN, c-Kit, c-Met, c-Myc, ALK, CK5/6, CK17, p53, EGFR, Ki67, p63 in triplenegative breast cancer-a single centre prospective observational study. In vivo (Athens, Greece). 2018;32(2):303-11.

42. Doberstein K, Milde-Langosch K, Bretz NP, Schirmer U, Harari A, Witzel I, et al. L1CAM is expressed in triple-negative breast cancers and is inversely correlated with androgen receptor. BMC Cancer. 2014;14:958.

43. Guiu S, Mollevi C, Charon-Barra C, Boissière F, Crapez E, Chartron E, et al. Prognostic value of androgen receptor and FOXA1 co-expression in nonmetastatic triple negative breast cancer and correlation with other biomarkers. Br J Cancer. 2018;119(1):76-9.

44. $\mathrm{Hu} X \mathrm{X}$, Chen $\mathrm{WL}, \mathrm{Ma} \mathrm{HG}$, Jiang K. Androgen receptor expression identifies patient with favorable outcome in operable triple negative breast cancer. Oncotarget. 2017;8(34):56364-74.

45. Kucukzeybek BB, Bayoglu IV, Kucukzeybek Y, YıIdı Y, Oflazoglu U, Atahan MK, et al. Prognostic significance of androgen receptor expression in HER2positive and triple-negative breast cancer. Polish J Pathol. 2018;69(2):157-68.

46. Sang M, Meng L, Ma C, Liu S, Sang M, Chang S, et al. Effect of AR antagonist combined with PARP1 inhibitor on sporadic triple-negative breast cancer bearing AR expression and methylation-mediated BRCA1 dysfunction. Biomedicine Pharmacotherapy. 2019;111:169-77.

47. Thike AA, Yong-Zheng Chong L, Cheok PY, Li HH, Wai-Cheong Yip G, Huat Bay $B$, et al. Loss of androgen receptor expression predicts early recurrence in triple-negative and basal-like breast cancer. Modern Pathol. 2014;27(3): $352-60$.

48. Zaborowski M, Pearson A, Sioson L, Gill AJ, Ahadi MS. Androgen receptor immunoexpression in triple-negative breast cancers: is it a prognostic factor? Pathology. 2019;51(3):327-9.

49. Vera-Badillo FE, Templeton AJ, de Gouveia P, Diaz-Padilla I, Bedard PL, AlMubarak M, et al. Androgen receptor expression and outcomes in early breast cancer: a systematic review and meta-analysis. J National Cancer Institute. 2014;106(1):djt319.

50. Bhattarai S, Klimov S, Mittal K, Krishnamurti U, Li XB, Oprea-llies G, et al. Prognostic role of androgen receptor in triple negative breast cancer: a multi-institutional study. Cancers. 2019;11(7).

51. Dehm SM, Tindall DJ. Alternatively spliced androgen receptor variants. Endocr Relat Cancer. 2011;18(5):R183-96.

52. Antonarakis ES, Lu C, Wang H, Luber B, Nakazawa M, Roeser JC, et al. AR-V7 and resistance to enzalutamide and abiraterone in prostate cancer. N Engl J Med. 2014:371(11):1028-38.

53. Hu R, Isaacs WB, Luo J. A snapshot of the expression signature of androgen receptor splicing variants and their distinctive transcriptional activities. Prostate. 2011;71(15):1656-67.

54. Zhan Y, Zhang G, Wang X, Qi Y, Bai S, Li D, et al. Interplay between cytoplasmic and nuclear androgen receptor splice variants mediates castration resistance. Mol Cancer Res. 2017;15(1):59-68.

55. Dehm SM, Schmidt LJ, Heemers HV, Vessella RL, Tindall DJ. Splicing of a novel androgen receptor exon generates a constitutively active androgen receptor that mediates prostate cancer therapy resistance. Cancer Res. 2008; 68(13):5469-77.

56. Visakorpi T, Hyytinen E, Koivisto P, Tanner M, Keinanen R, Palmberg C, et al. In vivo amplification of the androgen receptor gene and progression of human prostate cancer. Nat Genet. 1995;9(4):401-6.

57. Hickey TE, Irvine CM, Dvinge H, Tarulli GA, Hanson AR, Ryan NK, et al. Expression of androgen receptor splice variants in clinical breast cancers. Oncotarget. 2015;6(42):44728-44.

58. Krause WC, Shafi AA, Nakka M, Weigel NL. Androgen receptor and its splice variant, AR-V7, differentially regulate FOXA1 sensitive genes in LNCaP prostate cancer cells. Int J Biochem Cell Biol. 2014;54:49-59.

59. Hickey TE, Robinson JL, Carroll JS, Tilley WD. Minireview: the androgen receptor in breast tissues: growth inhibitor, tumor suppressor, oncogene? Molecular Endocrinol. 2012;26(8):1252-67.

60. Barton VN, Christenson JL, Gordon MA, Greene LI, Rogers TJ, Butterfield K, et al. Androgen receptor supports an anchorage-independent, cancer stem cell-like population in triple-negative breast cancer. Cancer Res. 2017;77(13): 3455-66.

61. Davis M, Tripathi S, Hughley R, He Q, Bae S, Karanam B, et al. AR negative triple negative or "quadruple negative" breast cancers in African American women have an enriched basal and immune signature. PLoS One. 2018; 13(6):e0196909-e.

62. Angajala A, Hughley R, Shweta T, Dean-Colomb W, Tan M, Yates C. Abstract A04: identification of differentially expressed micro-RNAs in African 
American women with quadruple-negative breast cancer. Cancer Epidemiology Biomarkers Prevention. 2018;27(7 Supplement):A04-A

63. Liu D, He J, Yuan Z, Wang S, Peng R, Shi Y, et al. EGFR expression correlates with decreased disease-free survival in triple-negative breast cancer: a retrospective analysis based on a tissue microarray. Medical Oncology. 2012; 29(2):401-5.

64. Masuda H, Zhang D, Bartholomeusz C, Doihara H, Hortobagyi GN, Ueno NT. Role of epidermal growth factor receptor in breast cancer. Breast Cancer Res Treat. 2012;136(2):331-45

65. Nakai K, Hung MC, Yamaguchi $H$. A perspective on anti-EGFR therapies targeting triple-negative breast cancer. Am J Cancer Res. 2016;6(8):1609-23.

66. Park HS, Jang MH, Kim EJ, Kim HJ, Lee HJ, Kim YJ, et al. High EGFR gene copy number predicts poor outcome in triple-negative breast cancer. Modern Pathol. 2014;27(9):1212-22.

67. Viale G, Rotmensz N, Maisonneuve P, Bottiglieri L, Montagna E, Luini A, et al. Invasive ductal carcinoma of the breast with the "triple-negative" phenotype: prognostic implications of EGFR immunoreactivity. Breast Cancer Res Treat. 2009;116(2):317-28.

68. Gasparini P, Fassan M, Cascione L, Guler G, Balci S, Irkkan C, et al. Androgen receptor status is a prognostic marker in non-basal triple negative breast cancers and determines novel therapeutic options. PLoS One. 2014;9(2): e88525.

69. Machleidt A, Buchholz S, Diermeier-Daucher S, Zeman F, Ortmann O, Brockhoff $\mathrm{G}$. The prognostic value of Her4 receptor isoform expression in triple-negative and Her2 positive breast cancer patients. BMC Cancer. 2013; 13:437.

70. Wang J, Yin J, Yang Q, Ding F, Chen X, Li B, et al. Human epidermal growth factor receptor 4 (HER4) is a favorable prognostic marker of breast cancer: a systematic review and meta-analysis. Oncotarget. 2016;7(47):76693-703.

71. Hsu YH, Yao J, Chan LC, Wu TJ, Hsu JL, Fang YF, et al. Definition of PKCalpha, CDK6, and MET as therapeutic targets in triple-negative breast cancer. Cancer Res. 2014;74(17):4822-35.

72. Keam B, Im SA, Lee KH, Han SW, Oh DY, Kim JH, et al. Ki-67 can be used for further classification of triple negative breast cancer into two subtypes with different response and prognosis. Breast Cancer Res. 2011;13(2):R22.

73. Pistelli M, Caramanti M, Biscotti T, Santinelli A, Pagliacci A, De Lisa M, et al. Androgen receptor expression in early triple-negative breast cancer: clinical significance and prognostic associations. Cancers. 2014;6(3):1351-62.

74. Safarpour D, Pakneshan S, Tavassoli FA. Androgen receptor (AR) expression in 400 breast carcinomas: is routine AR assessment justified? Am J Cancer Res. 2014;4(4):353-68.

75. Tsutsumi Y. Apocrine carcinoma as triple-negative breast cancer: novel definition of apocrine-type carcinoma as estrogen/progesterone receptornegative and androgen receptor-positive invasive ductal carcinoma. Jpn J Clin Oncol. 2012;42(5):375-86.

76. Urruticoechea A, Smith IE, Dowsett M. Proliferation marker Ki-67 in early breast cancer. J Clin Oncol. 2005;23(28):7212-20.

77. Lopez-Knowles E, O'Toole SA, McNeil CM, Millar EK, Qiu MR, Crea P, et al. PI3K pathway activation in breast cancer is associated with the basal-like phenotype and cancer-specific mortality. Int J Cancer. 2010;126(5):1121-31.

78. Nakagawa M, Bando Y, Nagao T, Morimoto M, Takai C, Ohnishi T, et al Expression of p53, Ki-67, E-cadherin, $\mathrm{N}$-cadherin and TOP2A in triplenegative breast cancer. Anticancer Res. 2011;31(6):2389-93.

79. Dai M, Zhang C, Ali A, Hong X, Tian J, Lo C, et al. CDK4 regulates cancer stemness and is a novel therapeutic target for triple-negative breast cancer. Sci Rep. 2016;6:35383.

80. Xu H, Yu S, Liu Q, Yuan X, Mani S, Pestell RG, et al. Recent advances of highly selective CDK4/6 inhibitors in breast cancer. J Hematol Oncol. 2017; 10(1):97.

81. Creighton CJ, Fu X, Hennessy BT, Casa AJ, Zhang Y, Gonzalez-Angulo AM, et al. Proteomic and transcriptomic profiling reveals a link between the PI3K pathway and lower estrogen-receptor (ER) levels and activity in ER+ breast cancer. Breast Cancer Res. 2010;12(3):R40.

82. Maloberti PM, Duarte AB, Orlando UD, Pasqualini ME, Solano AR, Lopez-Otin $C$, et al. Functional interaction between acyl-CoA synthetase 4 , lipooxygenases and cyclooxygenase-2 in the aggressive phenotype of breast cancer cells. PLoS One. 2010;5(11):e15540.

83. Monaco ME, Creighton CJ, Lee P, Zou X, Topham MK, Stafforini DM Expression of long-chain fatty Acyl-CoA synthetase 4 in breast and prostate cancers is associated with sex steroid hormone receptor negativity. Transl Oncol. 2010;3(2):91-8.
84. Orlando UD, Garona J, Ripoll GV, Maloberti PM, Solano AR, Avagnina A, et al The functional interaction between Acyl-CoA synthetase 4, 5-lipooxygenase and cyclooxygenase-2 controls tumor growth: a novel therapeutic target. PLoS One. 2012;7(7):e40794.

85. Wu X, Li Y, Wang J, Wen X, Marcus MT, Daniels G, et al. Long chain fatty Acyl-CoA synthetase 4 is a biomarker for and mediator of hormone resistance in human breast cancer. PLoS One. 2013;8(10):e77060.

86. Garcia-Teijido P, Cabal ML, Fernandez IP, Perez YF. Tumor-infiltrating lymphocytes in triple negative breast cancer: the future of immune targeting. Clin Med Insights Oncol. 2016;10(Suppl 1):31-9.

87. Fournier C, Martin F, Zitvogel L, Kroemer G, Galluzzi L, Apetoh L. Trial watch: adoptively transferred cells for anticancer immunotherapy. Oncoimmunology. 2017;6(11):e1363139.

88. Mittendorf EA, Philips AV, Meric-Bernstam F, Qiao N, Wu Y, Harrington S, et al. PD-L1 expression in triple-negative breast cancer. Cancer Immunol Research. 2014;2(4):361-70.

89. Stanton TR. Clinical prediction rules that don't hold up-where to go from here? J Orthopaedic Sports Physical Therapy. 2016;46(7):502-5.

90. Schaefer U, Voloshanenko O, Willen D, Walczak H. TRAlL: a multifunctional cytokine. Front Biosci. 2007;12:3813-24.

91. Castiel A, Visochek L, Mittelman L, Dantzer F, Izraeli S, Cohen-Armon M. A phenanthrene derived PARP inhibitor is an extra-centrosomes de-clustering agent exclusively eradicating human cancer cells. BMC Cancer. 2011;11:412.

92. Denu RA, Zasadil LM, Kanugh C, Laffin J, Weaver BA, Burkard ME. Centrosome amplification induces high grade features and is prognostic of worse outcomes in breast cancer. BMC Cancer. 2016;16:47.

93. Li Y, Lu W, Chen D, Boohaker RJ, Zhai L, Padmalayam I, et al. KIFC1 is a novel potential therapeutic target for breast cancer. Cancer Biology Therapy. 2015;16(9):1316-22.

94. Ogden A, Rida PC, Aneja R. Let's huddle to prevent a muddle: centrosome declustering as an attractive anticancer strategy. Cell Death Differ. 2012; 19(8):1255-67.

95. Ogden A, Rida PC, Aneja R. Prognostic value of CA20, a score based on centrosome amplification-associated genes, in breast tumors. Sci Rep. 2017; $7(1): 262$.

96. Pannu V, Mittal K, Cantuaria G, Reid MD, Li X, Donthamsetty S, et al. Rampant centrosome amplification underlies more aggressive disease course of triple negative breast cancers. Oncotarget. 2015;6(12):10487-97.

97. Raab MS, Breitkreutz I, Anderhub S, Ronnest MH, Leber B, Larsen TO, et al. GF-15, a novel inhibitor of centrosomal clustering, suppresses tumor cell growth in vitro and in vivo. Cancer Res. 2012;72(20):5374-85.

98. Watts CA, Richards FM, Bender A, Bond PJ, Korb O, Kern O, et al. Design, synthesis, and biological evaluation of an allosteric inhibitor of HSET that targets cancer cells with supernumerary centrosomes. Chem Biol. 2013; 20(11):1399-410.

99. Wu J, Mikule K, Wang W, Su N, Petteruti P, Gharahdaghi F, et al. Discovery and mechanistic study of a small molecule inhibitor for motor protein KIFC1. ACS Chem Biol. 2013;8(10):2201-8.

100. Masuda H, Baggerly KA, Wang Y, Zhang Y, Gonzalez-Angulo AM, MericBernstam F, et al. Differential response to neoadjuvant chemotherapy among 7 triple-negative breast cancer molecular subtypes. Clin Cancer Res. 2013;19(19):5533-40.

101. Jovanovic B, Mayer IA, Mayer EL, Abramson VG, Bardia A, Sanders ME, et al. A randomized phase II neoadjuvant study of cisplatin, paclitaxel with or without everolimus in patients with stage II/III triple-negative breast cancer (TNBC): responses and long-term outcome correlated with increased frequency of DNA damage response gene mutations, TNBC subtype, AR status, and Ki67. Clin Cancer Research. 2017;23(15):4035-45.

102. Hilborn E, Gacic J, Fornander T, Nordenskjold B, Stal O, Jansson A. Androgen receptor expression predicts beneficial tamoxifen response in oestrogen receptor-alpha-negative breast cancer. Br J Cancer. 2016;114(3):248-55.

103. Naorem LD, Muthaiyan M, Venkatesan A. Integrated network analysis and machine learning approach for the identification of key genes of triplenegative breast cancer. J Cell Biochem. 2019;120(4):6154-67.

104. Xiu J, Obeid E, Gatalica Z, Reddy S, Goldstein L, Link J, et al. Abstract P3-0726: biomarker comparison between androgen receptor - positive-triplenegative breast cancer (AR+ TNBC) and quadruple-negative breast cancer (QNBC). Cancer Res 2016;76(4 Supplement):P3-07-26-P3-07-26.

105. Johansson I, Aaltonen KE, Ebbesson A, Grabau D, Wigerup C, Hedenfalk I, et al. Increased gene copy number of KIT and VEGFR2 at $4 q 12$ in primary 
breast cancer is related to an aggressive phenotype and impaired prognosis. Genes, Chromosomes Cancer. 2012;51(4):375-83.

106. Jansson S, Bendahl PO, Grabau DA, Falck AK, Fernö M, Aaltonen K, et al. The three receptor tyrosine kinases C-KIT, VEGFR2 and PDGFRa, closely spaced at $4 q 12$, show increased protein expression in triple-negative breast cancer. PLoS One. 2014;9(7):e102176.

107. Curigliano G, Pivot X, Cortés J, Elias A, Cesari R, Khosravan R, et al. Randomized phase II study of sunitinib versus standard of care for patients with previously treated advanced triple-negative breast cancer. Breast 2013; 22(5):650-6.

108. Finn RS, Bengala C, Ibrahim N, Roché H, Sparano J, Strauss LC, et al. Dasatinib as a single agent in triple-negative breast cancer: results of an open-label phase 2 study. Clin Cancer Res. 2011;17(21):6905-13.

109. Soria JC, DeBraud F, Bahleda R, Adamo B, Andre F, Dientsmann R, et al. Phase I/lla study evaluating the safety, efficacy, pharmacokinetics, and pharmacodynamics of lucitanib in advanced solid tumors. Ann Oncol. 2014; 25(11):2244-51.

110. Tolaney SM, Ziehr DR, Guo H, Ng MR, Barry WT, Higgins MJ, et al. Phase II and biomarker study of cabozantinib in metastatic triple-negative breast cancer patients. Oncologist. 2017;22(1):25-32.

111. Abbaspour Babaei M, Kamalidehghan B, Saleem M, Huri HZ, Ahmadipour F. Receptor tyrosine kinase (c-Kit) inhibitors: a potential therapeutic target in cancer cells. Drug Des Devel Ther. 2016;10:2443-59.

112. Siddiqui A, Gollavilli PN, Schwab A, Vazakidou ME, Ersan PG, Ramakrishnan $M$, et al. Thymidylate synthase maintains the de-differentiated state of triple negative breast cancers. Cell Death Differ. 2019;26(11):2223-36.

113. Hollern DP, Swiatnicki MR, Rennhack JP, Misek SA, Matson BC, McAuliff A, et al. E2F1 drives breast cancer metastasis by regulating the target gene FGF13 and altering cell migration. Scientific Reports. 2019;9(1):10718.

114. Valle BL, D'Souza T, Becker KG, Wood WH 3rd, Zhang Y, Wersto RP, et al. Non-steroidal anti-inflammatory drugs decrease E2F1 expression and inhibit cell growth in ovarian cancer cells. PLoS One. 2013;8(4):e61836.

115. Engelmann D, Mayoli-Nussle D, Mayrhofer C, Furst K, Alla V, Stoll A, et al. E2F1 promotes angiogenesis through the VEGF-CNEGFR-3 axis in a feedback loop for cooperative induction of PDGF-B. J Mol Cell Biol. 2013; 5(6):391-403.

116. Qin G, Kishore R, Dolan CM, Silver M, Wecker A, Luedemann CN, et al. Cell cycle regulator E2F1 modulates angiogenesis via p53-dependent transcriptional control of VEGF. Proc Natl Acad Sci U S A. 2006;103(29): 11015-20.

117. Linderholm BK, Hellborg H, Johansson U, Elmberger G, Skoog L, Lehtio J, et al. Significantly higher levels of vascular endothelial growth factor (VEGF) and shorter survival times for patients with primary operable triple-negative breast cancer. Ann Oncol. 2009;20(10):1639-46.

118. Niu G, Wright KL, Huang M, Song L, Haura E, Turkson J, et al. Constitutive Stat3 activity up-regulates VEGF expression and tumor angiogenesis. Oncogene. 2002;21(13):2000-8.

119. Carey L, Winer E, Viale G, Cameron D, Gianni L. Triple-negative breast cancer: disease entity or title of convenience? Nat Rev Clin Oncol. 2010; 7(12):683-92.

120. Boddy JL, Fox SB, Han C, Campo L, Turley H, Kanga S, et al. The androgen receptor is significantly associated with vascular endothelial growth factor and hypoxia sensing via hypoxia-inducible factors HIF-1a, HIF-2a, and the prolyl hydroxylases in human prostate cancer. Clin Cancer Research. 2005; 11(21):7658-63.

121. Gilkes DM, Semenza GL. Role of hypoxia-inducible factors in breast cancer metastasis. Future oncology (London, England). 2013;9(11):1623-36.

122. Noh S, Kim JY, Koo JS. Metabolic differences in estrogen receptor-negative breast cancer based on androgen receptor status. Tumour Biol. 2014;35(8): 8179-92.

123. McDonald PC, Winum JY, Supuran CT, Dedhar S. Recent developments in targeting carbonic anhydrase IX for cancer therapeutics. Oncotarget. 2012; 3(1):84-97.

124. Wang F, Chang M, Shi Y, Jiang L, Zhao J, Hai L, et al. Down-regulation of hypoxia-inducible factor-1 suppresses malignant biological behavior of triple-negative breast cancer cells. Int J Clin Exp Med. 2014;7(11):3933-40.

125. Onnis B, Rapisarda A, Melillo G. Development of HIF-1 inhibitors for cancer therapy. J Cell Mol Med. 2009;13(9a):2780-6.

126. Arsenic R. Immunohistochemical analysis of PDK1 expression in breast cancer. Diagn Pathol. 2014;9:82
127. Maurer M, Su T, Saal LH, Koujak S, Hopkins BD, Barkley CR, et al. 3Phosphoinositide-dependent kinase 1 potentiates upstream lesions on the phosphatidylinositol 3-kinase pathway in breast carcinoma. Cancer Res. 2009:69(15):6299-306.

128. Du J, Yang M, Chen S, Li D, Chang Z, Dong Z. PDK1 promotes tumor growth and metastasis in a spontaneous breast cancer model. Oncogene. 2016;35(25):3314-23

129. Emmanouilidi A, Falasca M. Targeting PDK1 for chemosensitization of cancer cells. Cancers. 2017;9(10):140.

130. O'Hayre M, Salanga CL, Handel TM, Allen SJ. Chemokines and cancer: migration, intracellular signalling and intercellular communication in the microenvironment. Biochem J. 2008;409(3):635-49.

131. Fang WB, Yao M, Brummer G, Acevedo D, Alhakamy N, Berkland C, et al. Targeted gene silencing of CCL2 inhibits triple negative breast cancer progression by blocking cancer stem cell renewal and M2 macrophage recruitment. Oncotarget. 2016;7(31):49349-67.

132. Soto-Perez-de-Celis E, Chavarri-Guerra Y, Leon-Rodriguez E, GamboaDominguez A. Tumor-associated neutrophils in breast cancer subtypes. Asian Pacific J Cancer Prevention. 2017;18(10):2689-93.

133. Sousa S, Brion R, Lintunen M, Kronqvist P, Sandholm J, Monkkonen J, et al. Human breast cancer cells educate macrophages toward the M2 activation status. Breast Cancer Res. 2015;17:101.

134. Yu T, Di G. Role of tumor microenvironment in triple-negative breast cancer and its prognostic significance. Chin J Cancer Res. 2017;29(3):237-52.

135. Dannenmann SR, Thielicke J, Stockli M, Matter C, von Boehmer L, Cecconi V, et al. Tumor-associated macrophages subvert T-cell function and correlate with reduced survival in clear cell renal cell carcinoma. Oncoimmunology. 2013;2(3):e23562.

136. Henkels KM, Muppani NR, Gomez-Cambronero J. PLD-specific smallmolecule inhibitors decrease tumor-associated macrophages and neutrophils infiltration in breast tumors and lung and liver metastases. PLoS One. 2016;11(11):e0166553.

137. Mantovani A, Marchesi F, Malesci A, Laghi L, Allavena P. Tumour-associated macrophages as treatment targets in oncology. Nat Rev Clin Oncol. 2017; 14(7):399-416.

138. Rangel-Sosa MM, Aguilar-Córdova E, Rojas-Martínez A. Immunotherapy and gene therapy as novel treatments for cancer. Colomb Med (Cali). 2017;48(3): 138-47.

139. Shi Y, Yang F, Sun Z, Zhang W, Gu J, Guan X. Differential microRNA expression is associated with androgen receptor expression in breast cancer. Mol Med Rep. 2017;15(1):29-36.

140. Jinesh GG, Flores ER, Brohl AS. Chromosome 19 miRNA cluster and CEBPB expression specifically mark and potentially drive triple negative breast cancers. PLoS One. 2018;13(10):e0206008.

141. Cummins EP, Taylor CT. Hypoxia-responsive transcription factors. Pflugers Archiv : Eur J Physiol. 2005:450(6):363-71.

142. Peluffo G, Subedee A, Harper NW, Kingston N, Jovanovic B, Flores F, et al, EN1 is a transcriptional dependency in triple-negative breast cancer associated with brain metastasis. Cancer Res. 2019;79(16):4173-83.

143. Kim YJ, Sung M, Oh E, Vrancken MV, Song J-Y, Jung K, et al. Engrailed 1 overexpression as a potential prognostic marker in quintuple-negative breast cancer. Cancer biology \& therapy. 2018;19(4):335-45.

144. Sorolla A, Wang E, Clemons TD, Evans CW, Plani-Lam JH, Golden E, et al. Triple-hit therapeutic approach for triple negative breast cancers using docetaxel nanoparticles, EN1-iPeps and RGD peptides. Nanomedicine. 2019; 20:102003.

145. Wang Z, Fukushima H, Inuzuka H, Wan L, Liu P, Gao D, et al. Skp2 is a promising therapeutic target in breast cancer. Front Oncol. 2012;1(57):57.

146. Li B, Lu W, Yang Q, Yu X, Matusik RJ, Chen Z. Skp2 regulates androgen receptor through ubiquitin-mediated degradation independent of Akt/ mTOR pathways in prostate cancer. Prostate. 2014;74(4):421-32.

147. Signoretti S, Di Marcotullio L, Richardson A, Ramaswamy S, Isaac B, Rue M, et al. Oncogenic role of the ubiquitin ligase subunit Skp2 in human breast cancer. J Clin Invest. 2002:110(5):633-41.

148. Sun YJ, Wang XK, Li BJ. S-phase kinase-associated protein 2 expression interference inhibits breast cancer cell proliferation. Genetics Molecular Res. 2015;14(3):9244-52.

149. Wang H, Sun D, Ji P, Mohler J, Zhu L. An AR-Skp2 pathway for proliferation of androgen-dependent prostate-cancer cells. J Cell Sci. 2008;121(Pt 15): 2578-87. 
150. Yang C, Nan H, Ma J, Jiang L, Guo Q, Han L, et al. High Skp2/Low p57(Kip2) expression is associated with poor prognosis in human breast carcinoma. Breast Cancer. 2015;9(Suppl 1):13-21.

151. Wu L, Grigoryan AV, Li Y, Hao B, Pagano M, Cardozo TJ. Specific small molecule inhibitors of Skp2-mediated p27 degradation. Chem Biol. 2012; 19(12):1515-24.

\section{Publisher's Note}

Springer Nature remains neutral with regard to jurisdictional claims in published maps and institutional affiliations. 